\title{
The intrinsic antimicrobial activity of citric acid- coated manganese ferrite nanoparticles is enhanced after conjugation with the antifungal peptide $\mathrm{Cm}-\mathrm{p} 5$
}

This article was published in the following Dove Press journal:

International Journal of Nanomedicine

9 August 2016

Number of times this article has been viewed

\begin{abstract}
Carlos Lopez-Abarrategui,'
Viviana Figueroa-Espi, ${ }^{2}$ Maria B

Lugo-Alvarez,' Caroline D

Pereira, ${ }^{3}$ Hilda Garay, ${ }^{4}$ João

ARG Barbosa, ${ }^{5}$ Rosana Falcão, ${ }^{6}$

Linnavel Jiménez-Hernández, ${ }^{2}$

Osvaldo Estévez-Hernández, 2,7

Edilso Reguera, ${ }^{8}$ Octavio L

Franco, ${ }^{3,9}$ Simoni C Dias, ${ }^{3}$

Anselmo J Otero-Gonzalez'

'Faculty of Biology, Center for Protein Studies, ${ }^{2}$ Lab of Structural Analysis, Institute of Materials Science and Technology, Havana University, La Habana, Havana, Cuba; ${ }^{3}$ Center for Biochemical and Proteomics Analyses, Catholic University of Brasilia, Brasilia, Brazil; ${ }^{4}$ Laboratory of Peptide Analysis and Synthesis, Center of Genetic Engineering and Biotechnology, La Habana, Havana, Cuba; ${ }^{5}$ Department of Cellular Biology, Laboratory of Biophysics, Institute of Biological Science, University of Brasilia, ${ }^{6}$ Brazilian Agricultural Research Corporation (EMBRAPA), Center of Genetic Resources and Biotechnology (CENARGEN), Brasilia DF, Brazil; ' Instituto de Ciencia y Tecnología de Materiales (IMRE), Universidad de La Habana, Cuba; ${ }^{8}$ Research Center for Applied Science and Advanced Technology (CICATA), Nationa Polytechnic Institute (IPN), Lagaria Unit, Mexico DF, Mexico; ${ }^{9}$ S-Inova Biotech, PostGraduate in Biotechnology, Universidade Catolica Dom Bosco, Campo Grande, Brazil
\end{abstract}

Correspondence: Simoni C Dias Center for Biochemical and Proteomics Analyses, Catholic University of Brasilia, SGAN 916, Avenue W5, Brasilia, DF, Brazil, CEP 70790-I60

Email simoni@ucb.br

Anselmo J Otero-Gonzalez

Center for Protein Studies, Faculty of Biology,

Havana University, 25 Street x J street.

Vedado, 10400 Havana City, Cuba

Email aotero@fbio.uh.cu
Abstract: Diseases caused by bacterial and fungal pathogens are among the major health problems in the world. Newer antimicrobial therapies based on novel molecules urgently need to be developed, and this includes the antimicrobial peptides. In spite of the potential of antimicrobial peptides, very few of them were able to be successfully developed into therapeutics. The major problems they present are molecule stability, toxicity in host cells, and production costs. A novel strategy to overcome these obstacles is conjugation to nanomaterial preparations. The antimicrobial activity of different types of nanoparticles has been previously demonstrated. Specifically, magnetic nanoparticles have been widely studied in biomedicine due to their physicochemical properties. The citric acid-modified manganese ferrite nanoparticles used in this study were characterized by high-resolution transmission electron microscopy, which confirmed the formation of nanocrystals of approximately $5 \mathrm{~nm}$ diameter. These nanoparticles were able to inhibit Candida albicans growth in vitro. The minimal inhibitory concentration was $250 \mu \mathrm{g} / \mathrm{mL}$. However, the nanoparticles were not capable of inhibiting Gram-negative bacteria (Escherichia coli) or Gram-positive bacteria (Staphylococcus aureus). Finally, an antifungal peptide (Cm-p5) from the sea animal Cenchritis muricatus (Gastropoda: Littorinidae) was conjugated to the modified manganese ferrite nanoparticles. The antifungal activity of the conjugated nanoparticles was higher than their bulk counterparts, showing a minimal inhibitory concentration of $100 \mu \mathrm{g} / \mathrm{mL}$. This conjugate proved to be nontoxic to a macrophage cell line at concentrations that showed antimicrobial activity.

Keywords: nanoparticles, conjugation, antifungal, Cm-p5 peptide

\section{Introduction}

In recent decades, several new infectious diseases have emerged or reemerged. In many cases, they have been the origin for entirely new and life-threatening infectious emergencies. ${ }^{1,2}$ The absence of effective antibiotics for the treatment of certain illnesses combined with the appearance of multidrug-resistance in related strains has prompted even greater urgency for innovative approaches in the control of infections. Antimicrobial peptides (AMPs) form part of the first line of defense against pathogens of many organisms. Their use as anti-infective tools represents a novel approach for the development of antimicrobial therapies. ${ }^{4,5}$ Even though such peptides have been shown to be both broad spectrum (having antimicrobial, anticancer, immunomodulatory, wound healing and angiogenesis properties) and significantly potent in preclinical studies, this success has not been transmitted to clinical practice yet. ${ }^{6}$ The major disadvantages of AMPs have been low stability, cytotoxicity, biodistribution, and high production costs. ${ }^{4,7}$ 
Development of nanoparticles for delivery or conjugation of AMPs could represent an alternative to bypass the abovementioned clinical obstacles. ${ }^{8}$ In fact, the antimicrobial activity of different types of nanoparticles has been demonstrated. Some metals like silver, zinc, and copper exhibit antibacterial properties themselves, increasing the effect of these metals at nanoscale dimensions. ${ }^{9}$ Magnetic nanoparticles (MNPs) could be a suitable carrier for AMPs due to their wide spectrum of activities (anticancer, antimicrobial, drug delivery, diagnosis) and their low toxicity demonstrated in vivo. ${ }^{10-12}$ The potential applications of manganese ferrite nanoparticles $\left(\mathrm{MnFe}_{2} \mathrm{O}_{4}\right.$-NPs) for bioanalytical applications have been described, and it is perfectly possible to conjugate such nanoparticles to an anti-Sticholysin II monoclonal antibody, while preserving their antigenic recognition. ${ }^{13}$ The isostructural substitution of $\mathrm{Fe}$ (II) by $\mathrm{Mn}$ (II) in the magnetite structure provides the possibility of an enhanced peroxidaselike activity and a better material ability to participate in redox reactions, because the manganese ion has a large variety of available oxidation states, for example, $\mathrm{Mn}(\mathrm{III})$, $\mathrm{Mn}(\mathrm{IV}), \mathrm{Mn}(\mathrm{V}), \mathrm{Mn}(\mathrm{VII})$.

Furthermore, iron oxide (eg, magnetite and maghemite) is not antibacterial in its bulk form but may exhibit antibacterial properties in the form of nanoparticles. ${ }^{14}$ Such behavior is ascribed to the availability of a large fraction of the particle atoms at surface positions with an unsaturated coordination environment, and from this, enhanced reactivity. For example, magnetite nanoparticles coated with quaternary ammonium were bactericidal against Escherichia coli. ${ }^{15}$ Additionally, bacitracin-conjugated iron oxide $\left(\mathrm{Fe}_{3} \mathrm{O}_{4}\right)$ nanoparticles have shown higher antimicrobial activity against both Gram-positive and Gram-negative organisms, in comparison with the bacitracin peptide. ${ }^{16}$ Additionally, ceragenin CSA-13-coated MNPs (MNP-CSA-13) exhibited strong antibacterial activity and the ability to prevent bacterial biofilm formation in different body fluids, with a significant decrease in its hemolytic activity when the molecule was immobilized on the nanoparticle surface. ${ }^{17}$ In contrast, it has been reported that iron-containing nanoparticles may influence the ability of bacteria to absorb iron for growth, increase virulence, and inhibit AMP function. ${ }^{18}$

Here, we present the intrinsic antifungal activity of the citric acid-coated $\mathrm{MnFe}_{2} \mathrm{O}_{4}$-NPs and the improvement of their antifungal activity when these nanoparticles were conjugated with a 12 aa peptide named Cm-p5. ${ }^{19}$ This peptide is derived from Cm-p1, which is an MS-MS sequence found in a tryptic chromatographic fraction from the whole animal extract (Cenchritis muricatus [Gastropoda: Littorinidae], Linnaeus, 1758), which was positive for antimicrobial activity. We previously demonstrated that such sequence belongs to the original invertebrate, but we do not know if the corresponding peptide naturally acts as an AMP or if it is part of a major protein potentially undergoing cleavage by induction or not. ${ }^{20}$ From this sequence we obtained, by bioinformatics, the sequence and corresponding synthetized peptide $\mathrm{Cm}-\mathrm{p} 5$ with an increased antifungal activity. Therefore, we have based our thinking on previous results in which Cm-p5 showed a minimal loss of activity after conjugation with our manganese ferrite nanoparticles, taking into account that the nonimmunogenic small size of the peptide and its hydrophilicity are probably working together in accordance with our purposes.

\section{Materials and methods Nanoparticles (modified $\mathrm{MnFe}_{2} \mathrm{O}_{4}$ )}

Modified $\mathrm{MnFe}_{2} \mathrm{O}_{4}$-NPs used in this work were supplied by the Institute of Materials Science and Technology, University of Havana, Havana, Cuba. These nanoparticles were part of a batch characterized by X-ray diffraction (XRD), Mössbauer spectroscopy, and Fourier-transform infrared (IR) spectroscopy by Figueroa-Espi et al. ${ }^{13}$ In brief, XRD patterns were recorded in the Bragg-Brentano geometry using $\mathrm{K}_{\alpha 1}$ radiation. Mössbauer spectrum was collected at room temperature (RT) in the transmission geometry using a ${ }^{57} \mathrm{Co} / \mathrm{Rh}$ radiation source and provided information on the substitution of Fe(II) by $\mathrm{Mn}$ (II) in the spinel-type structure of the host magnetite framework.

\section{Characterization of MNPs by transmission electron microscopy}

The size of the MNPs was assessed by transmission electron microscopy (TEM). TEM images were obtained using a Jeol Jem 2010 F30 microscope (JEOL USA, Inc., Peabody, MA, USA) operated at $200 \mathrm{kV}$. Samples for TEM were prepared by letting a drop of the samples dispersed in ethanol evaporate on top of a carbon-coated copper grid of 200 meshes. Micrographs were taken by a Gatan Orius SC200 high-speed digital camera (Gatan, Inc., Pleasanton, CA, USA).

\section{Dynamic light scattering measurements}

Dynamic light scattering (DLS) measurements were made on a Zetasizer Nano ZS (Malvern Instruments, Malvern, UK) for particle size determination. The temperature of the sample cell was controlled to $20^{\circ} \mathrm{C}$ by a thermostating system. A He-Ne laser with $\lambda=633 \mathrm{~nm}$ was used to measure data at $173^{\circ}$ noninvasive backscattering using PCS8501 glass cuvette with round aperture. The experiments were performed 
using the nanoparticles in Tris-HCl buffer, $\mathrm{pH}$ 8.0. The final concentrations of the nanoparticles were $2 \mathrm{mg} / \mathrm{mL}$.

\section{Peptide synthesis}

Cm-p5 was obtained by solid-phase synthesis using 9-fluorenyl-methoxycarbonyl chemistry, ${ }^{21}$ purified by reversed-phase high-performance liquid chromatography to $>98 \%$ purity using an acetonitrile $/ \mathrm{H}_{2} \mathrm{O}$-trifluoroacetic acid gradient. Purity was evaluated by ion-spray mass spectrometry (Micromass, Manchester, UK).

\section{Determination of peptide concentration}

Peptide concentrations were estimated by ultraviolet absorption at 205, 215, and $225 \mathrm{~nm}$ (Abs205, Abs215, Abs225) using the following equations: ${ }^{22}$

$$
\begin{gathered}
\mathrm{C}(\mathrm{mg} / \mathrm{mL})=(\mathrm{A}+\mathrm{B}) / 2 \\
\mathrm{~A}=(\mathrm{Abs} 215-\mathrm{Abs} 225) \times 0.144 \\
\mathrm{~B}=(\mathrm{Abs} 205) \times 0.31
\end{gathered}
$$

\section{Conjugation of $\mathrm{Cm}-\mathrm{p} 5$ with modified $\mathrm{MnFe}_{2} \mathrm{O}_{4}-\mathrm{NPs}$}

$\mathrm{MnFe}_{2} \mathrm{O}_{4}$-NPs $4 \mathrm{mg}$ were activated by 1-ethyl-3(dimethylaminopropyl) carbodiimide/ $N$-hydroxysuccinimide solution $(0.5$ and $0.7 \mathrm{mg} / \mathrm{mL})$, respectively, in phosphatebuffered saline (PBS) for 30 minutes at RT. The activated nanoparticles were incubated with $0.4 \mathrm{mg}$ of peptide resuspended in $1 \mathrm{~mL}$ PBS and mixed at RT for 2 hours. The nanoparticles were washed twice in PBS and in 0.1 M Tris, $\mathrm{pH}$ 8.0.

\section{Antibacterial bioassays}

The antibacterial bioassays were evaluated for Staphylococcus aureus (ATCC29213) and E. coli (ATCC8739) by a colorimetric microreader (BioTek Instruments, Winooski, VT, USA) using 96-well microplates according to Hetru and Bulet's methodology. ${ }^{23}$ Bioassay analyses against bacteria were performed in Luria-Bertani medium ( $\mathrm{pH}$ 7.0). Previously, a growth curve of the original culture was established to determine the relationship between colony-forming units and optical density. For antimicrobial activity evaluation, $0.1 \mathrm{~mL}$ inoculum was cultured in $4 \mathrm{~mL}$ Luria-Bertani medium for 3 hours until it reached the mid-exponential phase. An aliquot corresponding to $5 \times 10^{5}$ colony-forming units/mL was then added to Luria-Bertani medium to produce a final volume of $0.1 \mathrm{~mL}$ in the microplate wells. Nanoparticles were added to reach a final concentration of $250 \mu \mathrm{g} / \mathrm{mL}$. Chloramphenicol at a concentration of $40 \mu \mathrm{g} / \mathrm{mL}$ and distilled water were used as positive and negative controls, respectively. Microplates were incubated at $37^{\circ} \mathrm{C}$, and bacterial growth was monitored at $620 \mathrm{~nm}$ every hour. The percentage of survival was determined as the ratio of optical density of normal bacterial growth (100\%) and the growth under nanoparticle action. All bioassays were performed in triplicate. To avoid potential optical interference during measurements of the growing cultures caused by the light-scattering properties of the nanoparticles, Luria-Bertani medium without microorganisms but containing the same concentration of nanoparticles cultured under the same conditions was used as a blank control.

\section{Antifungal bioassay}

Bioassays against yeast were performed using the broth microdilution method according to the Clinical and Laboratory Standards Institute guidelines. ${ }^{24}$ The bioassays against the clinically isolated strain of Candida albicans (01U) were performed in Roswell Park Memorial Institute (RPMI)-1640 medium (Thermo Fisher Scientific, Waltham, MA, USA). Amphotericin-B $(30 \mu \mathrm{g} / \mathrm{mL})$ and sterile distilled water were used as positive and negative controls, respectively. Microplates were incubated at $30^{\circ} \mathrm{C}$ and yeast growth was monitored at $620 \mathrm{~nm}$ every hour. The percent (\%) of survival was determined as the ratio of optical density of normal fungal growth (100\%) and the growth under peptide action. All tests were conducted in triplicate. The background (turbidity due to RPMI medium and MNPs suspension) was eliminated by taking blank readings. The citric acid-modified $\mathrm{MnFe}_{2} \mathrm{O}_{4}-$ NPs concentrations for the antifungal bioassay were 100 and $250 \mu \mathrm{g} / \mathrm{mL}$. The concentration of the citric acid-modified $\mathrm{MnFe}_{2} \mathrm{O}_{4}$-NPs conjugated with Cm-p5 was $100 \mu \mathrm{g} / \mathrm{mL}$ in comparison with Cm-p5 at $12 \mu \mathrm{g} / \mathrm{mL}$.

\section{Cytotoxicity assay}

Testing with 3-(4,5-dimethylthiazol-2-yl)-2,5-diphenyltetrazolium bromide (MTT, Sigma-Aldrich, St Louis, MO, USA) assay was performed according to Pasupuleti et al. ${ }^{25}$ RAW 264.7 murine macrophage-like cells (Rio de Janeiro Cell Bank, Rio de Janeiro, Brazil) were plated at a concentration of $1 \times 10^{5}$ cells per well in supplemented Dulbecco's Modified Eagle's Medium (4 mM glutamine, 10\% fetal calf serum, and 100 units/mL penicillin/streptomycin) and incubated with different concentrations of nanoparticles $(0-750 \mu \mathrm{g} / \mathrm{mL})$. After overnight incubation, $10 \mathrm{~mL}$ of the MTT solution $(5 \mathrm{mg} / \mathrm{mL}$ in PBS) was added to each well. Plates were incubated for 4 hours in $5 \% \mathrm{CO}_{2}$ at $37^{\circ} \mathrm{C}$. The generated blue formazan product was dissolved by the addition of $100 \mu \mathrm{L}$ of $100 \%$ dimethyl sulfoxide (Mallinckrodt Chemical, Paris, KY, USA) per well. The absorbance was monitored at $575 \mathrm{~nm}$ in an 
enzyme-linked immunosorbent assay plate reader (BioTek, Winooski, VT, USA). The citric acid-modified $\mathrm{MnFe}_{2} \mathrm{O}_{4}-\mathrm{NPs}$ concentrations for the viability and proliferation assay were 250, 500, and $750 \mu \mathrm{g} / \mathrm{mL}$.

\section{Interaction of modified $\mathrm{MnFe}_{2} \mathrm{O}_{4}-\mathrm{NPs}$ with $C$. albicans cells visualized by optical microscopy}

C. albicans cells were cultivated in the same way as described in the section of 'Antifungal bioassay'. Nanoparticles $(250 \mu \mathrm{g} / \mathrm{mL})$ were incubated for 1 hour with $C$. albicans $\left(10^{5}\right.$ cells $\left./ \mathrm{mL}\right)$ in RPMI-1640 medium at $30^{\circ} \mathrm{C}$. Observations were performed with an AxioPhot epifluorescence microscope equipped with an Axiocam MRc camera and complemented with capture software (AxioVision; Carl Zeiss GmbH, Jena, Germany).

\section{Results and discussion}

The $\mathrm{MnFe}_{2} \mathrm{O}_{4}$-NPs used in this study were prepared by microemulsion method. ${ }^{26}$ These nanoparticles were characterized by XRD, Mössbauer spectroscopy and high-resolution TEM
(HR-TEM) as previously described. ${ }^{13}$ XRD powder pattern corresponds to the face-centered cubic unit cell expected for manganese ferrite, which crystallizes with spinel-type structure. Figure 1 shows TEM micrographies, XRD pattern, and IR spectrum of manganese ferrite nanoparticles under study. Also, no evidence of accompanying phases was found. With the purpose of stabilizing the nanoparticles and creating reactive groups suitable for further conjugation procedures, $\mathrm{MnFe}_{2} \mathrm{O}_{4}$-NPs were modified with citric acid. As a sensing tool for the coating process, IR spectroscopy was used. The recorded IR spectra show several absorption bands characteristic of citrate groups (Figure 1). ${ }^{13}$

In order to study the crystalline nature of the modified $\mathrm{MnFe}_{2} \mathrm{O}_{4}$-NPs, HR-TEM images were obtained (Figure 1). We observed well-aligned atomic planes, demonstrating the uniformity of the obtained nanocrystals. The HR-TEM images confirm the formation of $\mathrm{MnFe}_{2} \mathrm{O}_{4}$ nanocrystals of about $5 \mathrm{~nm}$ diameter. This result is in agreement with Vestal et al, who used the same synthesis method and reported a nanoparticle diameter below $15 \mathrm{~nm} .{ }^{27}$ In the same sense, comparable diameter sizes of 4 and $5 \mathrm{~nm}$ for manganese
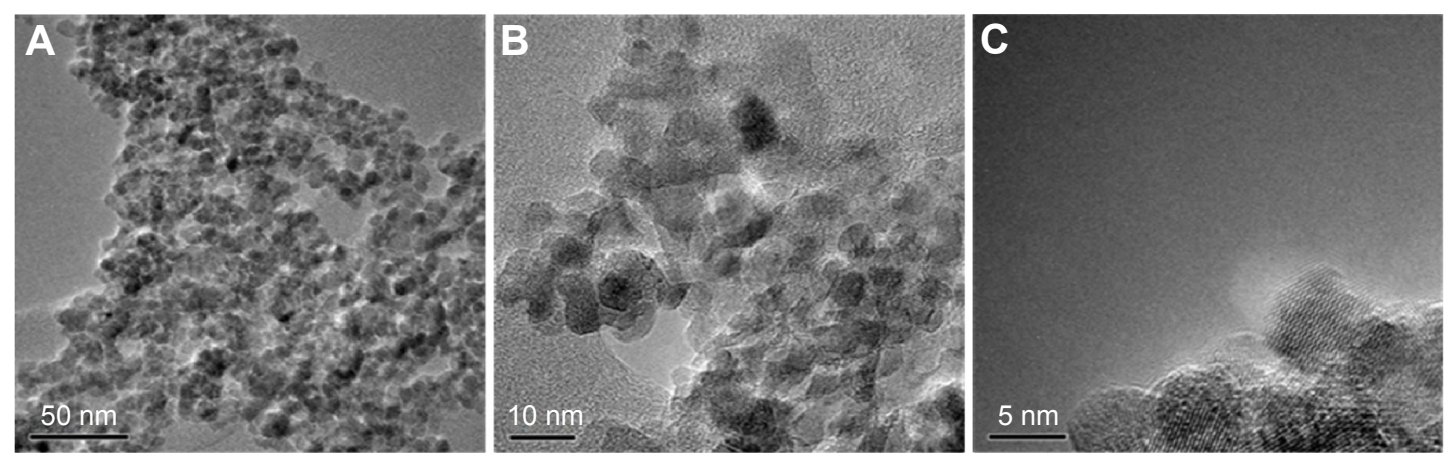

D

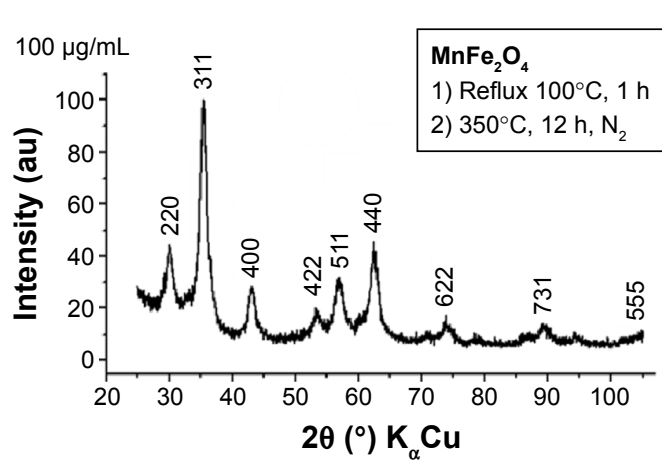

\section{E}

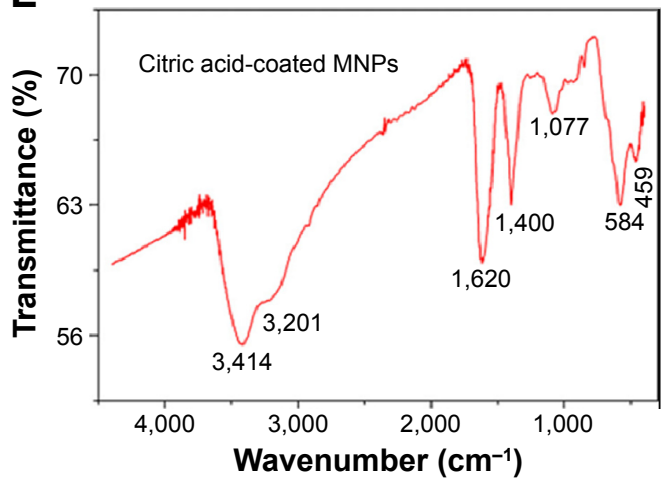

Figure I This material crystallizes with the face-centered cubic unit cell typical of spinel 3d metal oxides.

Notes: Their crystallite size, according to XRD and TEM images, remains below $12 \mathrm{~nm}$ (see Figure IC). The IR spectrum of citric acid-coated nanoparticles is conclusive regarding the anchoring of the organic molecule on the nanoparticles' surface. (A-C) HR-TEM micrographs at different resolutions from manganese ferrite nanocrystals. (D) XRD pattern. (E) IR spectrum of Mn-ferrite nanoparticles under study.

Abbreviations: IR, infrared; MNPs, magnetic nanoparticles; HR-TEM, high resolution transmission electron microscopy; XRD, X-ray diffraction. 
ferrite nanoparticles prepared by thermal decomposition have been reported. ${ }^{28,29}$

The measurements of the diameter of nanoparticles by DLS differ from HR-TEM analysis. The analysis by DLS shows that $93 \%$ of the NPs present a diameter range of 24-51 nm. Observed differences between both techniques are related with the fact that MNPs behave in solvents as a dispersion, in contrast to HR-TEM in which nanoparticles are analyzed as a dried sample. Similar results have been obtained by Nunes et al with citrate-coated manganese ferrite nanoparticles. ${ }^{30}$

The antimicrobial activity of different coated MNPs has been demonstrated. ${ }^{9} 14$ To this end, the citric acid-modified $\mathrm{MnFe}_{2} \mathrm{O}_{4}$-NPs were evaluated for their antimicrobial activity. These nanoparticles showed a significant antifungal activity against $C$. albicans at different concentrations (Figure 2). The minimal inhibitory concentration (MIC) of the MNPs was reached at $250 \mu \mathrm{g} / \mathrm{mL}$ in the RPMI medium. The antifungal activity of the nanoparticles was not fungicidal (data not shown). On the other hand, nanoparticles were not effective against the Gram-positive $S$. aureus and the Gram-negative E. coli bacteria (data not shown).

The antifungal activity of nanoparticles had been recently demonstrated for magnetic binary nanocomposites of iron oxide (magnetite and maghemite) and silver nanoparticles. ${ }^{31}$ These nanoparticles showed very significant antibacterial and antifungal activities against ten tested bacterial strains (MIC from 15.6 to $125 \mu \mathrm{g} / \mathrm{mL}$ ) and four Candida species (MIC from 1.9 to $31.3 \mu \mathrm{g} / \mathrm{mL}$ ). In this case, the inherent antimicrobial activity of silver can be taken into account, but on the other hand, some attempts to inhibit Candida biofilm formation succeeded by coating MNPs with plant essential oils applied to different surfaces as dressings and

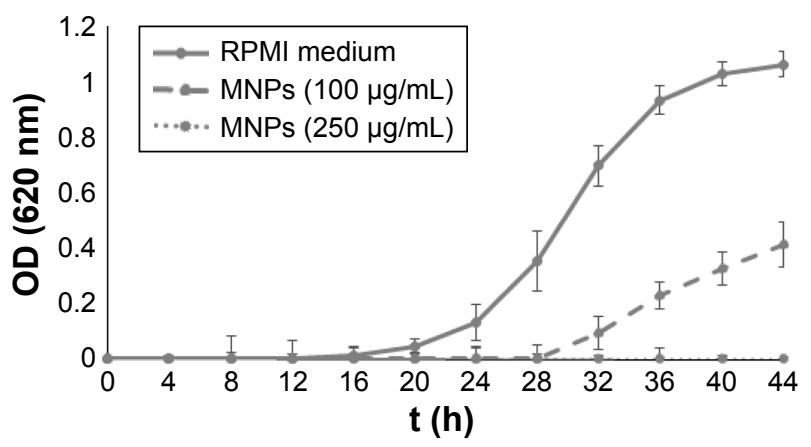

Figure 2 Candida albicans growth curves in RPMI-1640 medium using different concentrations of modified $\mathrm{MnFe}_{2} \mathrm{O}_{4}-\mathrm{NPs}$ in a final volume of $200 \mu \mathrm{L} /$ well.

Notes: Each value represents the mean of three replicates in three different experiments. Bars represent the standard deviation.

Abbreviations: MNPs, magnetic nanoparticles; OD, optical density; RPMI, Roswell Park Memorial Institute. medical devices. ${ }^{32-34}$ Nevertheless, no direct antifungal activity was demonstrated for these nanoparticles. In fact, no antimicrobial activity has been reported for "naked" MNPs. $\mathrm{MnFe}_{2} \mathrm{O}_{4}-\mathrm{NPs}$ have semiconductor behavior with a relatively low band gap, in the visible region, and for such reason, this nanoparticle system is unable to oxidize the water molecule producing radicals. In contrast, for instance, $\mathrm{TiO}_{2}$ and $\mathrm{ZnO}$ nanoparticles have a band gap in the ultraviolet region and the light absorption creates holes in the valence region, which are responsible for oxidizing the water and forming radicals, which are highly reactive species. In our work, it is probable that the antimicrobial activity of citric acid-modified $\mathrm{MnFe}_{2} \mathrm{O}_{4}$-NPs is related to such coating.

Indeed, the antibacterial activity of citric acid solutions has been previously reported. ${ }^{35-37}$ For example, the conjugation of citric acid to ciprofloxacin significantly improved the antibacterial activity of the antibiotic. ${ }^{38}$ However, the nanoparticles described in this paper were not effective against bacteria. It is possible that this effect could be related to the electrostatic repulsion between citrate groups on the surface of nanoparticles and the transmembrane potential of bacteria. In this sense, it has been reported that positively charged MNPs coated with a chitosan polymeric matrix have the ability to bind to the bacteria cell surface, exerting antimicrobial activity. ${ }^{39}$ Taking into account the electrostatic differences between prokaryotic bacterial and eukaryotic fungal plasma membrane, ${ }^{40}$ the selectivity of citric acid-modified $\mathrm{MnFe}_{2} \mathrm{O}_{4}-\mathrm{NPs}$ could be explained in such terms. Indeed, the interaction of citric acid-adsorbed $\mathrm{CoFe}_{2} \mathrm{O}_{4}$ nanoparticles with artificial lipid membranes (1-palmitoyl-2-oleoyl-sn-glycero3-phosphocholine) was demonstrated..$^{41}$ This result is relevant in this context since phosphatidylcholine is the most abundant phospholipid in yeast membrane. The mechanism of action for most of the cationic AMPs (and also extendable to our manganese ferrite nanoparticles) depends on the interaction with the microbial membrane to promote membrane destabilization, and these agents can function in vivo but are not toxic to host cells. One explanation is that AMPs produced by mammals will not act on eukaryotic cells because of the cholesterol content of eukaryotic membranes. In contrast, microbial cell membranes are free of cholesterol. Because cholesterol is known to cause condensation of phospholipid bilayers, it might prevent these agents from penetrating into the cytoplasmic membrane of eukaryotic cells. Besides cholesterol, the asymmetric distribution of phospholipids in the cytoplasmic membrane of mammalian cells might also contribute to the insensitivity of eukaryotic cells to this attack. ${ }^{42}$ On the other hand, C. albicans plasma membrane 
presents ergosterol instead of cholesterol and a combination of phosphatidylcholine, phosphatidylinositol, phosphatidylserine, and phosphatidylethanolamine, not present in mammalian cells; this could favor the interaction with the Mn-ferrite nanoparticles and subsequent destabilization.

With the purpose of discarding any toxic activity of modified $\mathrm{MnFe}_{2} \mathrm{O}_{4}$-NPs against animal cells, a viability test was conducted. A dose-dependent influence on cell damage was found. Nanoparticles were seen to be nontoxic to a macrophage cell line at concentrations that showed antifungal activity ( $\leq 250 \mu \mathrm{g} / \mathrm{mL}$ ). Otherwise, higher concentrations ( $\geq 500 \mu \mathrm{g} / \mathrm{mL}$ ) affected the viability of such cells (Figure 3 ). As for our antifungal peptide Cm-p5, when it is in contact with $C$. albicans cells at a sub-MIC concentration, instead of causing disturbing the cell membrane, the orientation and concentration of peptide in the membrane stimulate a higher yeast growth than the control with only cells and medium. For this reason, nanoparticles at $250 \mu \mathrm{g} / \mathrm{mL}$, like AMPs under MIC concentrations, could favor the cell's uptake of nutrients. This argument needs to be more thoroughly explored.

In agreement with our results, manganese ferrite nanoparticles functionalized with citric acid, with a mean particle size of $8 \mathrm{~nm}$, demonstrated dose-dependent cytotoxic effects from a concentration of $50 \mu \mathrm{g} / \mathrm{mL}$, as seen in the MTT assay using the mouse Balb/3T3 fibroblast cell line. ${ }^{43}$

Additionally, citric acid-coated iron oxide nanoparticles showed cytotoxicity on SK-MEL-37 human melanoma cell line with an $\mathrm{IC}_{50}$ (half-maximal inhibitory concentration)

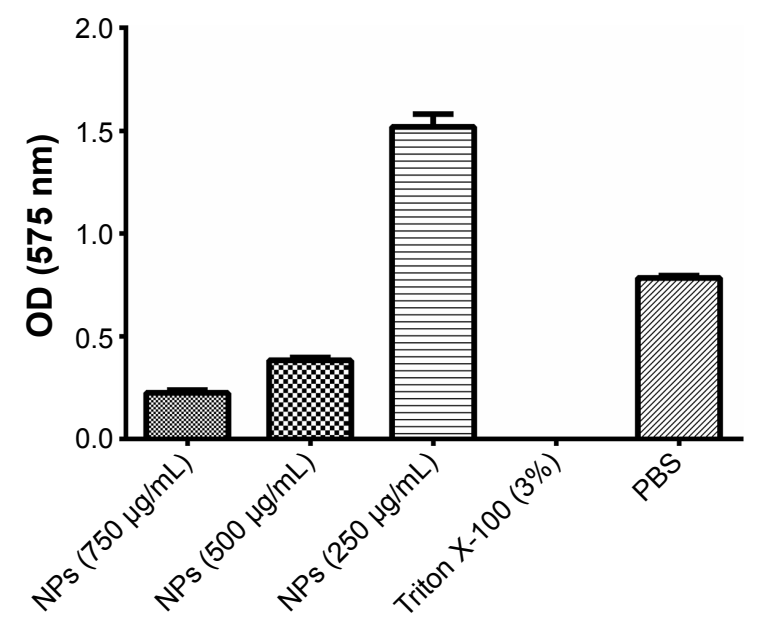

Figure 3 Viability and proliferation of the RAW 264.7 cells in RPMI- 1640 medium at different concentrations of citric acid-modified $\mathrm{MnFe}_{2} \mathrm{O}_{4}-\mathrm{NPs}$.

Notes: Triton X-100 (3\%) was used as a positive control for toxicity, and PBS was used as a negative control. Each column represents the mean of three replicates. Bars represent the standard deviation.

Abbreviations: $\mathrm{MnFe}_{2} \mathrm{O}_{4}-\mathrm{NPs}$, manganese ferrite nanoparticles; NPs, nanoparticles; OD, optical density; PBS, phosphate-buffered saline; RPMI, Roswell Park Memorial Institute. value of $433 \mu \mathrm{g} \mathrm{Fe} / \mathrm{mL}^{44}$ Indeed, COOH-modified iron oxide nanoparticles have shown some toxicity in human epithelial carcinoma cell lines at a concentration of $10 \mu \mathrm{g} / \mathrm{mL} \cdot{ }^{45,46} \mathrm{This}$ behavior can be explained by the charge on the surface of iron oxide nanoparticles, which could play an important role in the intracellular uptake. ${ }^{47}$ In this sense, there was no observable uptake of citrate-coated MNPs at concentrations of up to $0.1 \mathrm{mg} / \mathrm{mL}$ for murine macrophage cells (RAW 264.7) and Jurkat cell line (clone E6-1). At concentrations until $0.6 \mathrm{mg} / \mathrm{mL}$, a relevant cellular uptake was observed, but the uptake of nanoparticles did not affect the viability and proliferation of the cells. At higher concentrations, cell viability decreased markedly. ${ }^{48}$

Furthermore, after exposing endothelial cells to citric acid-coated iron oxide nanoparticles, dose-dependent effects on human umbilical vein endothelial cells' viability, cytoskeleton, and function were demonstrated. ${ }^{49}$ On the other hand, cationic polymeric manganese ferrite nanoparticles exhibited higher cytotoxicity in macrophages (RAW 264.7 cells) and lower cellular membrane rigidity than anionic and nonionic polymeric manganese ferrite nanoparticles. ${ }^{50}$ In general, the toxicity of magnetic particles may depend on different factors, including the concentration, composition, size, structure, solubility, and surface chemistry. ${ }^{51}$

In order to explore the antifungal effect of citric acidmodified $\mathrm{MnFe}_{2} \mathrm{O}_{4}$-NPs, microscopy studies of $C$. albicans cells grown in RPMI medium in the presence of modified nanoparticles were performed. As shown in Figure 4, C. albicans growth inhibition by MNPs may have occurred due to the aggregation of yeast cells. More experiments are necessary to study such an interaction further.

In agreement with our results, MNPs coated with aminated silica were able to interact with the surface of the fungus Fusarium oxysporum. In this case, no antifungal action was detected. ${ }^{52}$

Taking into account the intrinsic antifungal activity found for the citric acid-functionalized manganese ferrites, we explored the antimicrobial activity of these nanoparticles conjugated with the antifungal peptide $\mathrm{Cm}-\mathrm{p} 5$. The efficiency of the carbodiimide-based conjugation was above $80 \%$. This type of coupling chemistry has been used for immobilizing AMPs by their amino groups. ${ }^{53,54}$ Significantly, the antifungal activity of the conjugated nanoparticles was higher than that of their bulk counterparts (Figure 5). In fact, the MIC of Cm-p5 conjugated to $\mathrm{MnFe}_{2} \mathrm{O}_{4}-\mathrm{NPs}$ was $100 \mu \mathrm{g} / \mathrm{mL}$, which was 2.5 times lower than the MIC of nonconjugated nanoparticles (Figure 5A). On the other hand, with 7.5 times less Cm-p5 in the conjugate regarding the soluble peptide, 

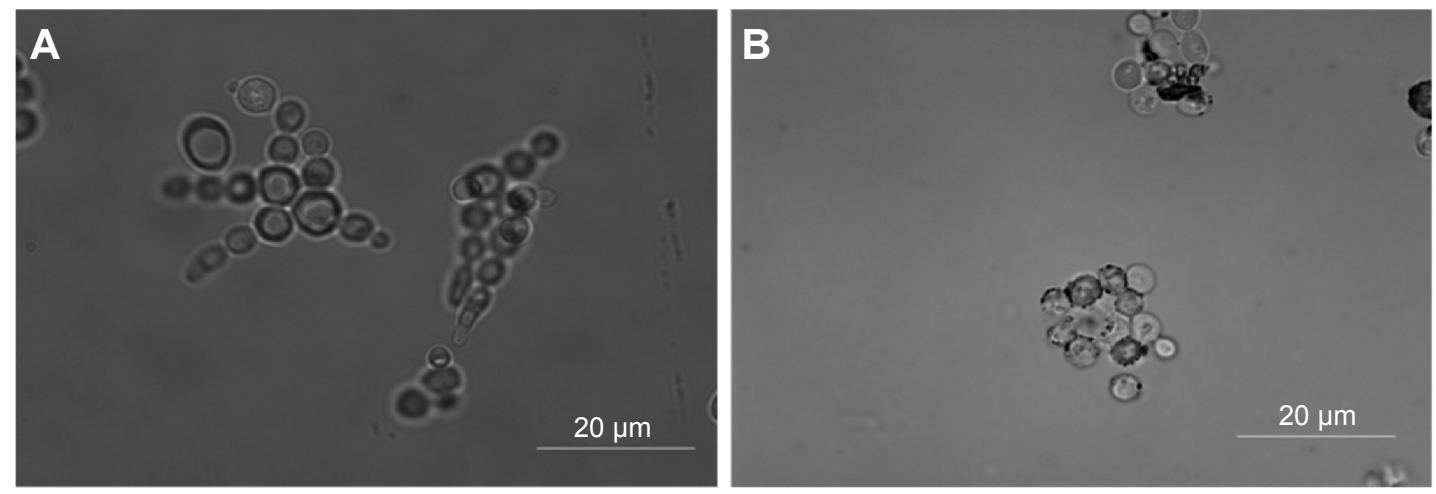

Figure 4 Interaction of modified $\mathrm{MnFe}_{2} \mathrm{O}_{4}$-NPs with Candida albicans cells visualized by optical microscopy.

Notes: (A) C. albicans cells ( $10^{5}$ cells $\left./ \mathrm{mL}\right)$ in RPMI- 1640 medium at $30^{\circ} \mathrm{C}$. (B) C. albicans cells $\left(10^{5} \mathrm{cells} / \mathrm{mL}\right)$ in RPMI- 1640 medium at $30^{\circ} \mathrm{C}$ with citric acid-modified MnFe $\mathrm{O}_{4}{ }^{-}$ NPs $(250 \mu \mathrm{g} / \mathrm{mL})$.

Abbreviations: $\mathrm{MnFe}_{2} \mathrm{O}_{4}-\mathrm{NPs}$, manganese ferrite nanoparticles; RPMI, Roswell Park Memorial Institute.

complete C. albicans growth inhibition was achieved (Figure 5B).

These results differ from the work of other authors, who reported that the activity of AMPs decreased upon conjugation to different supports. ${ }^{55-58}$ Indeed, Borcherding et al reported that iron-containing nanoparticles affect the activity of soluble AMPs, probably influenced by the ability of bacteria to scavenge iron for growth from nanoparticles and the adsorption of peptides onto nanoparticle surfaces. ${ }^{18}$ It is obvious that AMPs with different physicochemical properties can be affected differently by immobilization reactions. ${ }^{59}$

In this sense, Cm-p5 is not an amphipathic peptide, and its antifungal activity does not depend on its amino-terminal group. ${ }^{19}$ Also, the mechanism of action of this peptide is related to interactions with the fungal cell surface; therefore, it is possible to have a synergistic antifungal action in the conjugate between the peptide and MNPs. In the same way, the immobilization of the AMP nisin to multiwalled carbon nanotubes improved the antibacterial and antibiofilm properties of noncoated carbon nanotubes. ${ }^{60}$ Furthermore, bacitracin-conjugated iron oxide nanoparticles showed higher antibacterial activity than bacitracin alone. Because of this improved activity, conjugated MNPs allow lower dosages and fewer collateral effects of the antibiotic. ${ }^{16}$ Finally, Cm-p5conjugated $\mathrm{MnFe}_{2} \mathrm{O}_{4}$-NPs showed a similar pattern of toxicity in the cell line RAW 264.7 as found for citric acid-modified $\mathrm{MnFe}_{2} \mathrm{O}_{4}$-NPs (data not shown), but less of the conjugate was needed to completely inhibit $C$. albicans growth.

\section{Conclusion}

These results contribute to marking the importance of MNPs in biomedicine, specifically in the antimicrobials field.
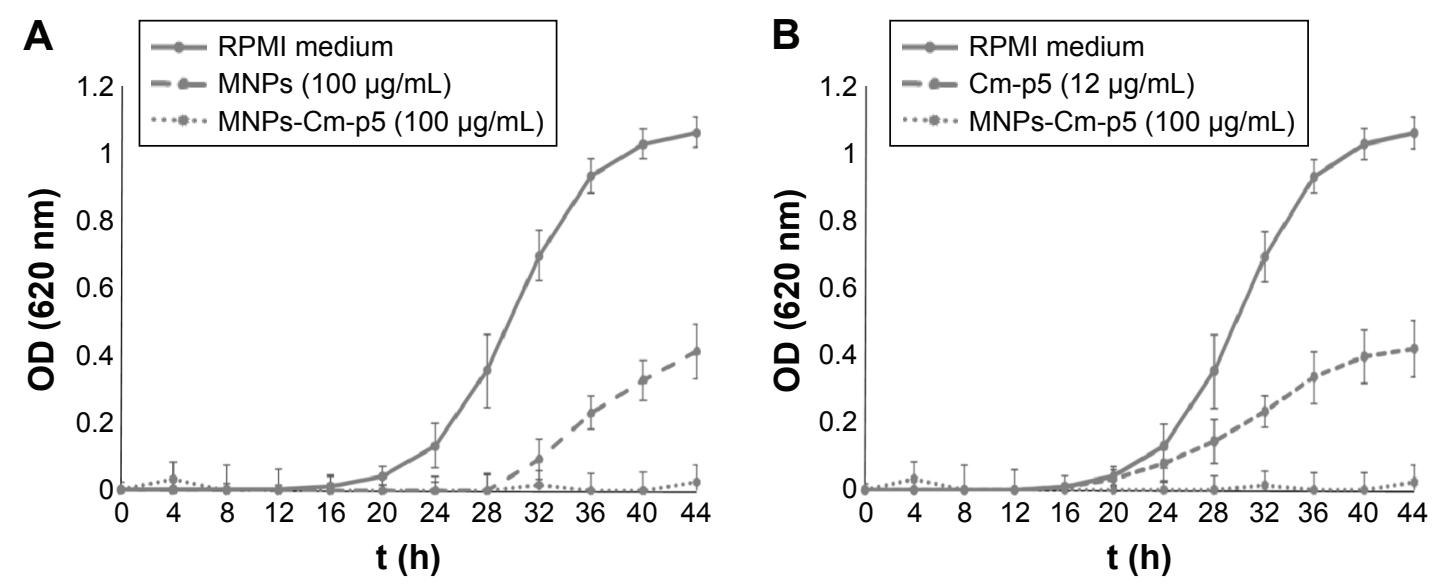

Figure 5 Antifungal activity assays.

Notes: (A) Candida albicans growth curves in RPMI-1640 medium of modified $\mathrm{MnFe}_{2} \mathrm{O}_{4}-\mathrm{NPs}$ and $\mathrm{Cm}$-p5-conjugated $\mathrm{MnFe}_{2} \mathrm{O}_{4}-\mathrm{NPs}$. Each value represents the mean of three replicates in three different experiments. Bars represent the standard deviation. (B) C. albicans growth curves in RPMI-I640 medium of the Cm-p5 peptide and $\mathrm{Cm}$-p5-conjugated $\mathrm{MnFe}_{2} \mathrm{O}_{4}-\mathrm{NPs}$. Each value represents the mean of three replicates in three different experiments. Bars represent the standard deviation. Abbreviations: MNPs, magnetic nanoparticles; $\mathrm{MnFe}_{2} \mathrm{O}_{4}-\mathrm{NPs}$, manganese ferrite nanoparticles; OD, optical density; RPMI, Roswell Park Memorial Institute. 
Herein, the intrinsic antifungal activity of citric acid-coated $\mathrm{MnFe}_{2} \mathrm{O}_{4}$-NPs was demonstrated. In addition, the improvement of their antifungal activity was achieved when these nanoparticles were conjugated with the AMP Cm-p5. Nowadays, strategies are required to reduce the toxicity and enhance the efficacy and biodistribution of AMPs. MNPs could be an excellent alternative due to their broad spectrum of activities (antimicrobial, drug delivery, diagnosis) and their low toxicity.

\section{Acknowledgments}

The authors thank FAPDF (Support Research of the Federal District Foundation, Brasilia DF, Brazil), FUNDECT (Support Foundation The Education Development, Science and Technology state of Mato Grosso do Sul, Brazil), and CAPES-MES (Higher Education Personnel Improvement Coordination-Ministry of Higher Education), Brazil; International Foundation of Science, Sweden (F 4614 and F/5199 projects).

\section{Disclosure}

The authors report no conflicts of interest in this work.

\section{References}

1. Kruijshaar ME, Watson JM, Drobniewski F, et al. Increasing antituberculosis drug resistance in the United Kingdom: analysis of National Surveillance Data. BMJ. 2008;336(7655):1231-1234.

2. Snell NJ. Examining unmet needs in infectious disease. Drug Discov Today. 2003;8(1):22-30.

3. Arias CA, Murray BE. Antibiotic-resistant bugs in the 21 st century - a clinical super-challenge. N Engl J Med. 2009;360(5):439-443.

4. Afacan NJ, Yeung AT, Pena OM, Hancock RE. Therapeutic potential of host defense peptides in antibiotic-resistant infections. Curr Pharm Des. 2012;18:807-819.

5. Riedl S, Zweytick D, Lohner K. Membrane-active host defense peptideschallenges and perspectives for the development of novel anticancer drugs. Chem Phys Lipids. 2011;164:766-781.

6. Eckert R. Road to clinical efficacy: challenges and novel strategies for antimicrobial peptide development. Future Microbiol. 2011;6(6): 635-651.

7. Brogden NK, Brogden KA. Will new generations of modified antimicrobial peptides improve their potential as pharmaceuticals? Int $J$ Antimicrob Agents. 2011;38(3):217-225.

8. Brandelli A. Nanostructures as promising tools for delivery of antimicrobial peptides. Mini Rev Med Chem. 2012;12:731-741.

9. Lopez-Abarrategui C, Otero-Gonzalez AJ, Alba-Menendez A, Reguera E, Franco OL. Nanoparticles as a promise for host defense peptides therapeutics. In: Prokopovich P, editor. Biological and Pharmaceutical Applications of Nanomaterials. Boca Raton, FL: CRC Press; 2015 : 129-147.

10. Lopez-Abarrategui C, Figueroa-Espi V, Reyes-Acosta O, Reguera E, Otero-Gonzalez AJ. Magnetic nanoparticles: new players in antimicrobial peptide therapeutics. Curr Protein Pept Sci. 2013;14(7):595-606.

11. Sabale S, Jadhav V, Khot V, Zhu X, Xin M, Chen H. Superparamagnetic $\mathrm{MFe}_{2} \mathrm{O}_{4}(\mathrm{M}=\mathrm{Ni}, \mathrm{Co}, \mathrm{Zn}, \mathrm{Mn})$ nanoparticles: synthesis, characterization, induction heating and cell viability studies for cancer hyperthermia applications. J Mater Sci Mater Med. 2015;26(3):5466.
12. Zottis AD, Beltrame JM, Lara LR, et al. Pheomelanin-coated iron oxide magnetic nanoparticles: a promising candidate for negative T2 contrast enhancement in magnetic resonance imaging. Chem Commun (Camb). 2015;51(56):11194-11197.

13. Figueroa-Espi V, Alvarez-Paneque A, Torrens M, Otero-Gonzalez AJ, Reguera E. Conjugation of manganese ferrite nanoparticles to an anti Sticholysin monoclonal antibody and conjugate applications. Colloid Surf A. 2011;387:118-124.

14. Liakos I, Grumezescu AM, Holban AM. Magnetite nanostructures as novel strategies for anti-infectious therapy. Molecules. 2014;19(8): 12710-12726.

15. Dong H, Huang J, Koepsel RR, Ye P, Russell AJ, Matyjaszewski K. Recyclable antibacterial magnetic nanoparticles grafted with quaternized poly(2-(dimethylamino)ethyl methacrylate) brushes. Biomacromolecules. 2011;12(4):1305-1311.

16. Zhang W, Shi X, Huang J, Zhang Y, Wu Z, Xian Y. Bacitracin-conjugated superparamagnetic iron oxide nanoparticles: synthesis, characterization and antibacterial activity. Chem Phys Chem. 2012;13(14): 3388-3396.

17. Niemirowicz K, Surel U, Wilczewska AZ, et al. Bactericidal activity and biocompatibility of ceragenin-coated magnetic nanoparticles. J Nanobiotechnology. 2015;13:32.

18. Borcherding J, Baltrusaitis J, Chen H, et al. Iron oxide nanoparticles induce growth, induce biofilm formation, and inhibit antimicrobial peptide function. Environ Sci Nano. 2014;1(2):123-132.

19. Lopez-Abarrategui C, McBeth C, Mandal SM, et al. Cm-p5: an antifungal hydrophilic peptide derived from the coastal mollusk Cenchritis muricatus (Gastropoda: Littorinidae). FASEB J. 2015;29:3315-3325.

20. Lopez-Abarrategui C, Alba A, Silva ON, et al. Functional characterization of a synthetic hydrophilic antifungal peptide derived from the marine snail Cenchritis muricatus. Biochimie. 2012;94(4):968-974.

21. Merrifield B. Solid phase synthesis. Science. 1986;232(4748):341-347.

22. Murphy J, Kies M. Note on the spectrophotometric determination of proteins in dilute solutions. Biochim Biophys Acta. 1960;3:382-384.

23. Hetru C, Bulet P. Strategies for the isolation and characterization of antimicrobial peptides of invertebrates. Methods Mol Biol. 1997;78: 35-49.

24. CLSI. Reference method for broth dilution antifungal susceptibility testing of yeasts. Approved Standard - Eighth Edition. Wayne, PA: Clinical and Laboratory Standards Institute; 2008.

25. Pasupuleti M, Schmidtchen A, Chalupka A, Ringstad L, Malmsten M. End-tagging of ultra-short antimicrobial peptides by W/F stretches to facilitate bacterial killing. PLoS One. 2009;4(4):e5285.

26. Alvarez-Paneque A, Díaz S, Santiago-Jacinto P, Reguera E. Síntesis y caracterización de nanopartículas magnéticas basadas en la $\mathrm{MnFe}_{2} \mathrm{O}_{4}$ tipo espinela [Synthesis and characterization of magnetic nanoparticles based on spinel type manganese ferrite $\mathrm{MnFe}_{2} \mathrm{O}_{4}$ ]. Rev Cub Física. 2008;25(2B):117-122.

27. Vestal CR, Zhang ZJ. Atom transfer radical polymerization synthesis and magnetic characterization of $\mathrm{MnFe}_{2} \mathrm{O}_{4} /$ polystyrene core/shell nanoparticles. J Am Chem Soc. 2002;124(48):14312-14313.

28. Hyun SW, Hong SC, Kim SJ, Kim CS. Effect of proton irradiation on the magnetic properties of manganese ferrite. J Nanosci Nanotechnol. 2011;11(7):6241-6244.

29. Pal M, Rakshit R, Mandal K. Surface modification of MnFe(2)O(4) nanoparticles to impart intrinsic multiple fluorescence and novel photocatalytic properties. ACS Appl Mater Interfaces. 2014;6(7):4903-4910.

30. Nunes AD, Ramalho LS, Souza AP, et al. Manganese ferrite-based nanoparticles induce ex vivo, but not in vivo, cardiovascular effects. Int J Nanomedicine. 2014;9:3299-3312.

31. Prucek R, Tucek J, Kilianova M, et al. The targeted antibacterial and antifungal properties of magnetic nanocomposite of iron oxide and silver nanoparticles. Biomaterials. 2011;32(21):4704-4713.

32. Anghel I, Grumezescu AM, Holban AM, Ficai A, Anghel AG, Chifiriuc MC. Biohybrid nanostructured iron oxide nanoparticles and Satureja hortensis to prevent fungal biofilm development. Int J Mol Sci. 2013;14:18110-18123. 
33. Chifiriuc C, Grumezescu V, Grumezescu AM, Saviuc C, Lazar V, Andronescu E. Hybrid magnetite nanoparticles/Rosmarinus officinalis essential oil nanobiosystem with antibiofilm activity. Nanoscale Res Lett. 2012;7:209.

34. Grumezescu AM, Chifiriuc MC, Saviuc C, et al. Hybrid nanomaterial for stabilizing the antibiofilm activity of Eugenia carryophyllata essential oil. IEEE Trans Nanobioscience. 2012;11(4):360-365.

35. Arias-Moliz MT, Ferrer-Luque CM, Espigares-Rodriguez E, LiebanaUrena J, Espigares-Garcia M. Bactericidal activity of phosphoric acid, citric acid, and EDTA solutions against Enterococcus faecalis. Oral Surg Oral Med Oral Pathol Oral Radiol Endod. 2008;106(2):e84-e89.

36. Kim SA, Rhee MS. Synergistic antimicrobial activity of caprylic acid in combination with citric acid against both Escherichia coli O157:H7 and indigenous microflora in carrot juice. Food Microbiol. 2015 49:166-172.

37. Ko KY, Mendonca AF, Ahn DU. Influence of zinc, sodium bicarbonate, and citric acid on the antibacterial activity of ovotransferrin against Escherichia coli O157:H7 and Listeria monocytogenes in model systems and ham. Poult Sci. 2008;87(12):2660-2670.

38. Milner SJ, Snelling AM, Kerr KG, et al. Probing linker design in citric acid-ciprofloxacin conjugates. Bioorg Med Chem. 2014;22(16): 4499-4505.

39. Chifiriuc CM, Grumezescu AM, Saviuc C, Croitoru C, Mihaiescu DE, Lazar V. Improved antibacterial activity of cephalosporins loaded in magnetic chitosan microspheres. Int J Pharm. 2012;436:201-205.

40. Matsuzaki K. Control of cell selectivity of antimicrobial peptides. Biochim Biophys Acta. 2008;1788(8):1687-1692.

41. Drasler B, Drobne D, Novak S, et al. Effects of magnetic cobalt ferrite nanoparticles on biological and artificial lipid membranes. Int $J$ Nanomedicine. 2014;9:1559-1581.

42. Lai Y, Gallo RL. AMPed up immunity: how antimicrobial peptides have multiple roles in immune defense. Trends Immunol. 2009;30: 131-141.

43. Bellusci M, La Barbera A, Padella F, et al. Biodistribution and acute toxicity of a nanofluid containing manganese iron oxide nanoparticles produced by a mechanochemical process. Int J Nanomedicine. 2014; 9:1919-1929.

44. de Freitas ER, Soares PR, Santos RP, et al. In vitro biological activities of anionic gamma- $\mathrm{Fe}_{2} \mathrm{O}_{3}$ nanoparticles on human melanoma cells. J Nanosci Nanotechnol. 2008;8(5):2385-2391.

45. Sharma G, Kodali V, Gaffrey M, et al. Iron oxide nanoparticle agglomeration influences dose rates and modulates oxidative stress-mediated dose-response profiles in vitro. Nanotoxicology. 2014;8:663-675.

46. Shen M, Cai H, Wang X, et al. Facile one-pot preparation, surface functionalization, and toxicity assay of APTS-coated iron oxide nanoparticles. Nanotechnology. 2012;23(10):105601.
47. Patil US, Adireddy S, Jaiswal A, Mandava S, Lee BR, Chrisey DB. In vitro/in vivo toxicity evaluation and quantification of iron oxide nanoparticles. Int J Mol Sci. 2015;16(10):24417-24450.

48. Srivastava S, Awasthi R, Gajbhiye NS, et al. Innovative synthesis of citrate-coated superparamagnetic $\mathrm{Fe}_{3} \mathrm{O}_{4}$ nanoparticles and its preliminary applications. J Colloid Interface Sci. 2011;359(1):104-111.

49. Wu X, Tan Y, Mao H, Zhang M. Toxic effects of iron oxide nanoparticles on human umbilical vein endothelial cells. Int J Nanomedicine. 2010;5:385-399.

50. Yang SH, Heo D, Park J, et al. Role of surface charge in cytotoxicity of charged manganese ferrite nanoparticles towards macrophages. Nanotechnology. 2012;23(50):505702.

51. Reddy LH, Arias JL, Nicolas J, Couvreur P. Magnetic nanoparticles: design and characterization, toxicity and biocompatibility, pharmaceutical and biomedical applications. Chem Rev. 2012;112(11): 5818-5878.

52. Rispail N, De Matteis L, Santos R, et al. Quantum dot and superparamagnetic nanoparticle interaction with pathogenic fungi: internalization and toxicity profile. ACS Appl Mater Interfaces. 2014;6(12): 9100-9110.

53. Chen G, Zhou M, Chen S, Lv G, Yao J. Nanolayer biofilm coated on magnetic nanoparticles by using a dielectric barrier discharge glow plasma fluidized bed for immobilizing an antimicrobial peptide. Nanotechnology. 2009;20(46):465706.

54. Costa F, Carvalho IF, Montelaro RC, Gomes P, Martins MC. Covalent immobilization of antimicrobial peptides (AMPs) onto biomaterial surfaces. Acta Biomater. 2011;7(4):1431-1440.

55. Bagheri M, Beyermann M, Dathe $M$. Immobilization reduces the activity of surface-bound cationic antimicrobial peptides with no influence upon the activity spectrum. Antimicrob Agents Chemother. 2009;53(3): 1132-1141.

56. Cho WM, Joshi BP, Cho H, Lee KH. Design and synthesis of novel antibacterial peptide-resin conjugates. Bioorg Med Chem Lett. 2007;17(21): 5772-5776.

57. Haynie SL, Crum GA, Doele BA. Antimicrobial activities of amphiphilic peptides covalently bonded to a water-insoluble resin. Antimicrob Agents Chemother. 1995;39(2):301-307.

58. Hilpert K, Elliott M, Jenssen H, et al. Screening and characterization of surface-tethered cationic peptides for antimicrobial activity. Chem Biol. 2009;16(1):58-69.

59. Vries R, Andrade CA, Bakuzis AF, Mandal SM, Franco OL. Nextgeneration nanoantibacterial tools developed from peptides. Nanomedicine (Lond). 2015;10(10):1643-1661.

60. Qi X, Poernomo G, Wang K, et al. Covalent immobilization of nisin on multi-walled carbon nanotubes: superior antimicrobial and anti-biofilm properties. Nanoscale. 2011;3(4):1874-1880.
International Journal of Nanomedicine

\section{Publish your work in this journal}

The International Journal of Nanomedicine is an international, peerreviewed journal focusing on the application of nanotechnology in diagnostics, therapeutics, and drug delivery systems throughout the biomedical field. This journal is indexed on PubMed Central, MedLine, CAS, SciSearch $®$, Current Contents $\AA /$ Clinical Medicine,

\section{Dovepress}

Journal Citation Reports/Science Edition, EMBase, Scopus and the Elsevier Bibliographic databases. The manuscript management system is completely online and includes a very quick and fair peer-review system, which is all easy to use. Visit http://www.dovepress.com/ testimonials.php to read real quotes from published authors. 